\title{
Mechanical Characterization of Cryomilled Al Powder Consolidated by High-Frequency Induction Heat Sintering
}

\author{
Ehab A. El-Danaf, ${ }^{1}$ Mahmoud S. Soliman, ${ }^{1}$ Abdulhakim A. Almajid, ${ }^{1,2}$ \\ and Khalil Abdelrazek Khali1 ${ }^{1}$ \\ ${ }^{1}$ Mechanical Engineering Department, College of Engineering, King Saud University, P.O. Box 800, Riyadh 11421, Saudi Arabia \\ ${ }^{2}$ Center of Excellence for Research in Engineering Materials, College of Engineering, King Saud University, P.O. Box 800, \\ Riyadh 11421, Saudi Arabia
}

Correspondence should be addressed to Mahmoud S. Soliman; solimanm@ksu.edu.sa

Received 16 April 2013; Accepted 17 June 2013

Academic Editor: Pavel Lejcek

Copyright (C) 2013 Ehab A. El-Danaf et al. This is an open access article distributed under the Creative Commons Attribution License, which permits unrestricted use, distribution, and reproduction in any medium, provided the original work is properly cited.

In the present investigation, an aluminum powder of $99.7 \%$ purity with particle size of $\sim 45 \mu \mathrm{m}$ was cryomilled for 7 hours. The produced powder as characterized by scanning, transmission electron microscopy, and X-ray diffraction gave a particle size of $\sim 1 \mu \mathrm{m}$ and grain (crystallite) size of $23 \pm 6 \mathrm{~nm}$. This powder, after degassing process, was consolidated using high-frequency induction heat sintering (HFIHS) at various temperatures for short periods of time of 1 to 3 minutes. The present sintering conditions resulted in solid compact with nanoscale grain size $(<100 \mathrm{~nm})$ and high compact density. The mechanical properties of a sample sintered at $773 \mathrm{~K}$ for 3 minutes gave a compressive yield and ultimate strength of 270 and $390 \mathrm{MPa}$, respectively. The thermal stability of grain size nanostructured compacts is in agreement with the kinetics models based on the thermodynamics effects.

\section{Introduction}

Interest in the field of nanocrystalline (nc) materials has grown tremendously in recent years. The technique under study is mechanical attrition (MA) of aluminum powders under constant flow of liquid nitrogen that is recognized as cryomilling. The most common consolidation route for these powders, to obtain a densified bulk material, was hot isostatic pressing (HIP) followed by hot extrusion $[1,2]$. The major problem with such route was the relatively prolonged time exposure at elevated temperature to achieve an acceptable level of densification, which would be accompanied by a considerable grain growth bringing the bulk material out of the nanocrystalline range $(>100 \mathrm{~nm})[2,3]$.

In general, some difficulties arise during ball milling of Al-based alloys when conventional ball milling techniques are employed because of the strong tendency of powder particles to adhere to container walls, to agglomerate, and to sinter to form large millimeter sized particles. The introduction of cryogenic liquid media during milling effectively eliminates these problems, demonstrating that cryomilling is capable of producing nanometer scaled microstructures in powders with a uniform particle size distribution. Details of cryomilling process are published elsewhere [3].

It is proposed $[4,5]$ that during mechanical milling, metal powder particles are subjected to severe plastic deformation from collision with milling balls. Consequently, plastic deformation at high strain rates occurs within the particles and the average grain size is reduced. The process leading to grain size reduction includes three basic stages. First the deformation is localized into shear bands consisting of high-density dislocations. Second, at a certain strain level, these dislocations annihilate and recombine as small angle grain boundaries. Finally, the small angle grain boundaries change their orientation under further deformation and randomly oriented nano-meter scale grains are formed. This mechanism was further elaborated upon by Xun et al. [6] and these steps were associated with three phenomena happening at specific structural scales: a macroscopic level (level of individual powders), a mesoscopic level (level of individual 
small fragments), and a microscopic level (level of individual grains). At the macroscopic level, the formation of a nc structure is accounted for by the repeated strain fatigue fracturing and cold welding caused by cycling impacting loading in random directions. Because the low milling temperature leads to transgranular fracture, the fracturing and cold welding are likely to refine grains by forming new grains at the welding interface from the fragments of the original coarse grains. At the mesoscopic level, individual fragments are refined through a bimodal process that is reflected in the following: (1) the plastic damage is surmised to occur via impacts from the balls and (2) the impact energy stored in the form of shear bands consisting of an array of dislocations with higher density. At the microscopic level, the starting grain is large in size (on the order of microns) and almost dislocation free. With increasing interior strain, the dislocation density increases gradually. At a certain strain level, these dislocations will form subboundaries by aligning, annihilating, and recombining with each other. With further deformation, the low angle sub-boundaries are changed to high-angle boundaries (true boundaries) by the absorption of more dislocations into the boundaries or accompanying grain rotation. Finally, the grain size reaches a given constant size. Once this size is reached, further refinement ceases. It is reported [4] that the milling time to reach the final stage was significantly shorter for cryomilling than that for conventional milling performed at ambient temperature, which was attributed to the suppression of the recovery effect at cryogenic temperature.

Many investigations $[4,6,7]$ were conducted to study the effect of milling time on grain size and the thermal stability of the cryomilled powders. Zawarh and Shaw [7] presented interesting results in which the crystallite size of aluminum alloy (Al-Fe-Cr-Ti) decreased with milling time. Lee at al. [4] studied the cryomilling of pure nickel powders of nominal particle size of $45 \mu \mathrm{m}$. They have reported the average grain size of cryomilled nickel as function of annealing temperature and time. It was shown that $\mathrm{Ni}$ grains were stable at $150 \mathrm{~nm}$, even after long annealing time, nearly 4 hours at a temperature of $973 \mathrm{~K}\left(0.56 T_{m}\right.$, where $T_{m}$ is the absolute melting temperature). The observed high thermal stability was attributed to grain boundary pinning mechanism arising from ultrafine $\mathrm{NiO}$ particles formed during cryomilling as well as impurity segregation. Also, a study on cryomilled Al $7.5 \% \mathrm{Mg}$ alloy indicated that the alloy remained thermally stable when annealed at $723 \mathrm{~K}[5,8]$. The origin of the exceptional grain size stability of milled aluminum powders has been attributed to pinning effects arising from aluminum oxide/nitride/carbide dispersoids as well as segregation of solute atoms to grain boundaries.

It was also demonstrated by $\mathrm{He}$ et al. [9] that mechanical milling can alter the expected deformation mechanism in high stacking fault energy (SFE) FCC materials. They showed the presence of induced deformation twinning in several milled FCC metals and alloys with high SFE (from 100 to $200 \mathrm{~mJ} / \mathrm{m}^{2}$ ). They ascertained the presence of nanoscale deformation twins in Inconel 625 powder cryomilled for 8 hours. It was concluded in another study [10] that deformation twinning could not occur in alloys with SFE higher than $25 \mathrm{~mJ} / \mathrm{m}^{2}$, in the case of quasistatic strain. However, the tendency for deformation twinning increases with increasing strain rate or decreasing temperature. Huang et al. [11] have studied the microstructure evolution of 304 stainless steel powder during mechanical milling and showed that, through saturation magnetization measurements, a strain-induced martensitic transformation occurs during milling.

The aim of this work is to study the cryomilling of 99.7\% purity aluminum powder at various milling times and evaluate the crystal size achieved. The selection of this powder is based on twofold: (i) this alloy is the base material for various commercial $\mathrm{Al}$ alloys and (ii) to compare cryomilling to other sever-plastic deformation techniques used to produce ultrafine grain size in the present alloy. A novel sintering technique was employed, namely, highfrequency induction heat sintering (HFIHS), in which the sintering temperature was reached in less than 2 minutes, while maintaining a constant pressure of $50 \mathrm{MPa}$, for 1 and 3 minutes as a sintering time. This sintering technique was selected to examine the possibility of minimizing grain growth in consolidated powders.

\section{Experimental Procedures}

The powder used in the present investigation was of the chemical composition of $99.7 \% \mathrm{Al}$ with impurities (wt.\%) of $0.15 \mathrm{Fe}, 0.1 \mathrm{Si}$, and minor impurities of 0.05 . The cryomilling is conducted in a 1 gallon 304 stainless steel tank in an attritor procured from Union Process, USA. A ratio of 1:30 powder to stainless steel ball weight ratio was used. In addition, $0.2 \mathrm{wt} . \%$ stearic acid was added to the powders in the vial at the beginning, as a process control agent to minimize cold welding of particles. The impeller is rotated at $150 \mathrm{rpm}$ and then the balls are charged followed by the powders and stearic acid, and then the valve for liquid nitrogen flow is opened for maintaining a liquid nitrogen media in the milling vial during the whole attrition period. The rotation of the shaft is then increased to $250 \mathrm{rpm}$. After the intended milling time of 2, 5, and 7 hours, the powder is collected in slurry form from a valve underneath the milling vial. The slurry is then dried in a drying vacuum oven at a temperature of $250^{\circ} \mathrm{C}$ and a vacuum level of $\sim 10^{-4}$ torr for 3 hours. The powder after drying is checked for crystal size by the X-diffraction using Xray line broadening techniques proposed by Scherrer $[12,13]$.

The equation developed by Scherrer to calculate the crystallite size " $d$ " from a diffraction peak is presented below as (1). The $B_{\text {Struc }}$ used in the equation is the broadening of the diffracted peak due to the crystallite size, assuming an unstrained crystallite. To deconvolute the contribution of the instrument to this broadening, a standard, which is assumed to have negligible broadening from the crystallite size, is measured. In (2), the broadening due to the crystallite size, $B_{\text {Struc }}$, is calculated from the full width at half maximum (FWHM) of the standard's diffracted peak, $B_{\text {Resolution, and }}$ the measured FWHM of the sample, $B_{\text {Observed }}$. The standard 


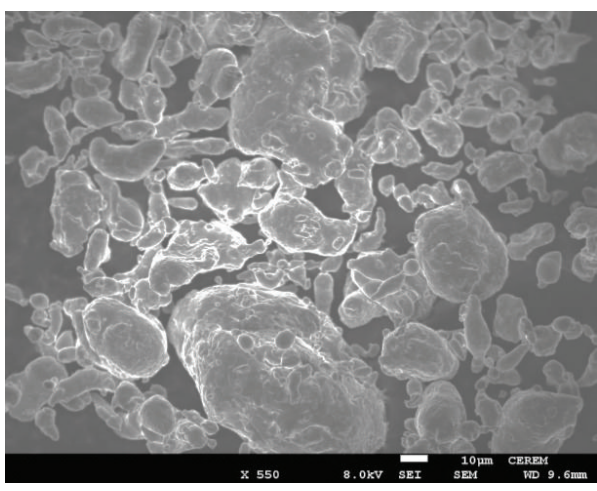

(a)

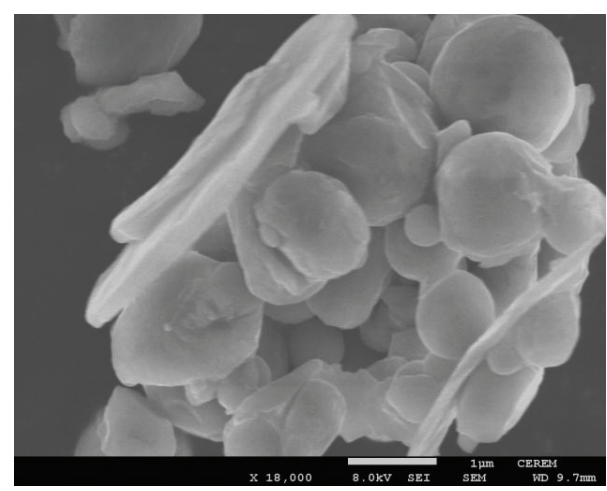

(b)

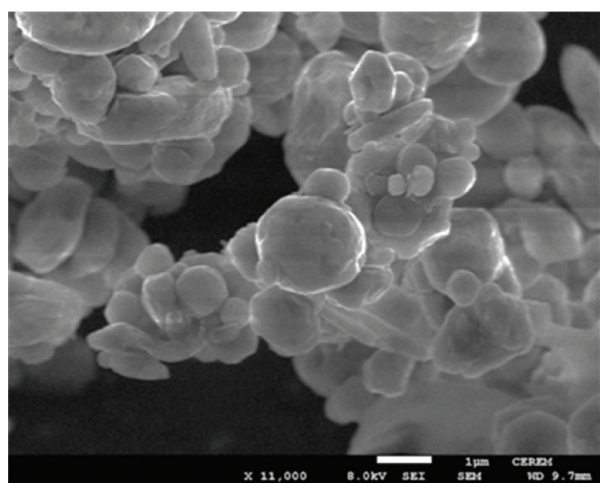

(c)

FIGURE 1: FESEM secondary electron images of as-received Al powder in (a) and Al powder that was produced by cryomilling for 7 hours in (b) and (c). Note the difference in magnification.

sample is strain-free silicon single crystal that is used to correct for instrumental broadening as

$$
\begin{gathered}
d=\frac{0.9 \lambda}{B_{\text {Struc }} \operatorname{Cos} \theta}, \\
B_{\text {Struc }}=\sqrt{\left(B_{\text {Observed }}^{2}-B_{\text {Resolution }}^{2}\right)} .
\end{gathered}
$$

In (1), $\lambda$ is the wavelength of $\mathrm{Cu} \mathrm{K}_{\alpha}$ radiation $(0.154 \mathrm{~nm})$; $\theta$ (in degrees) is half the position $2 \theta$ of the diffracted peak. All $B$ values must be expressed in radians. In addition, the ascryomilled powder samples were examined using transmission electron microscopy (TEM). TEM sample preparation consisted of suspending the nanostructured powders in methanol, agitating the solution by hand, and submersing a $\mathrm{Cu}$ TEM grid into the methanol where the powders adhered to it. Micrographs of the powders were produced using a JOEL JEM $7600 \mathrm{~F}$ transmission electron microscope operated at $200 \mathrm{kV}$. Average grain size was determined directly from the TEM micrographs by measuring the diameters of 300 grains for each sample. Bright field TEM images were used for this grain size determination following the procedures of Zhou et al. [14].

The dried powders were consolidated by HFIHS in graphite dies under a constant pressure of $50 \mathrm{MPa}$ in a vacuum chamber of $10^{-3}$ torr. The induced current frequency was approximately $50 \mathrm{kHz}$ based on previous study [15]. The sintering conditions were varied among sintering temperatures $\left(350-550^{\circ} \mathrm{C}\right.$ ) and sintering times ( 1 and $3 \mathrm{~min}$.). The crystal size was checked after cryomilling and drying and also after consolidation using the X-ray line broadening.

The density of consolidated samples was measured by means of Archimedes' principle. Hardness measurements were done using a Vickers microhardness test machine. A load of $200 \mathrm{~g}$ and a dwell time of $15 \mathrm{sec}$ were used. Five measurements were taken across the face of the consolidated samples, and the values are reported as an average with error of $\pm 5 \%$. The mechanical behavior of consolidated samples was investigated by compression testing using an Instron universal testing machine (model 3385) at room temperature and at a cross-head speed corresponding to initial strain rate of $5 \times 10^{-4} \mathrm{~s}^{-1}$ up to the failure of specimens. Teflon sheet and high pressure grease were used, under compression to nearly isolate the effect of friction from the output data. The deformed specimens showed very little barreling (less than $2 \%)$.

\section{Results and Discussion}

Figure 1 is a field-emission scanning electron microscope (FESEM) image of the as-received Al powder and that cryomilled for 7 hours. The particle size of the as-received powder is in the rage of $5-80 \mu \mathrm{m}$ with an average particle size 


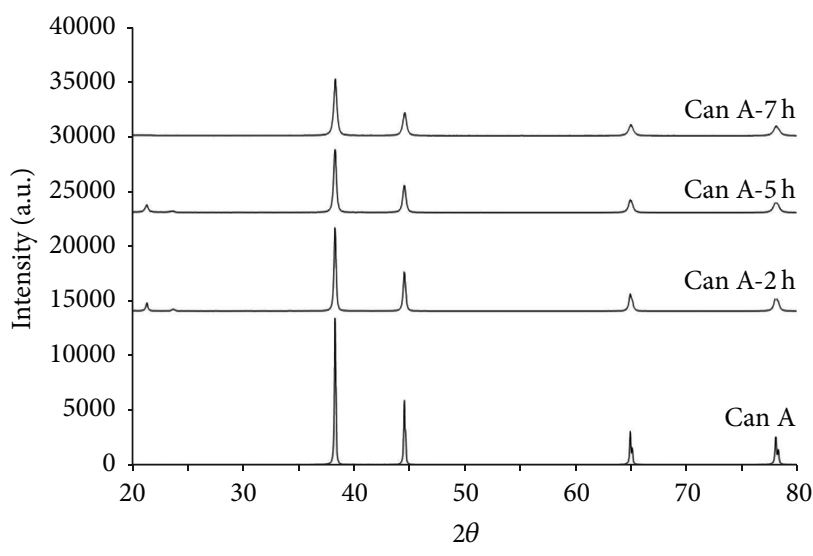

(a)

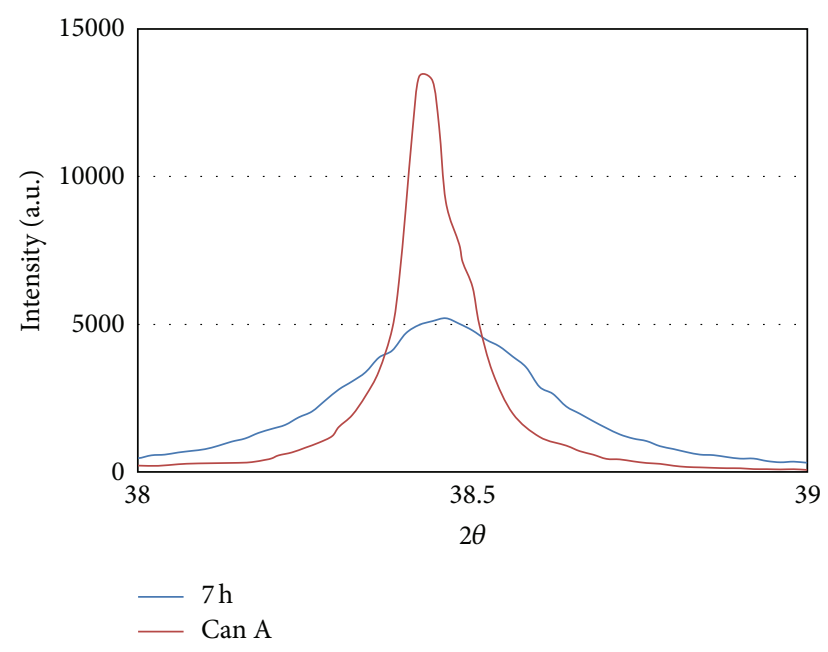

(b)

FIGURE 2: (a) XRD patterns for the cryomilled powders to different milling times, (b) the (111) XRD peak for the powders cryomilled for 7 hours and the standard sample.

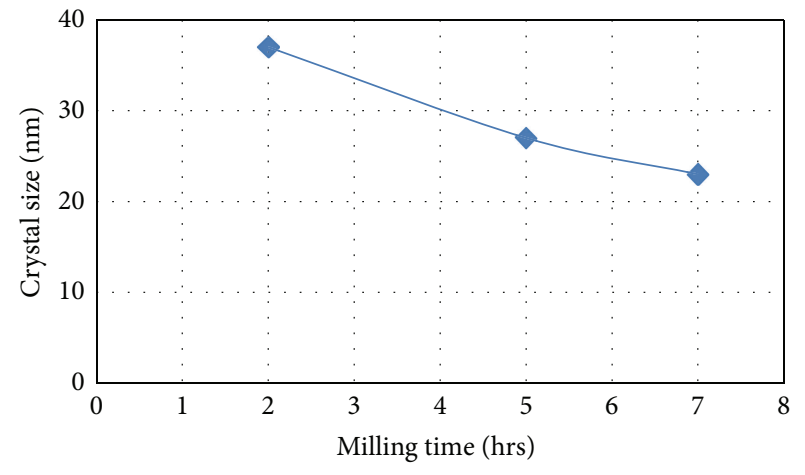

FIGURE 3: Variation of crystal size for the powders with milling time.

of $\sim 45 \mu \mathrm{m}$. The figure shows also the shape of the particles after cryomilling for $7 \mathrm{~h}$. After cryomilling, the shape of the particles is almost spherical with few particles with flakelike shape. The average size of cryomilled particles is $\sim 1 \mu \mathrm{m}$. Figure 2(a) presents the XRD patterns for the powders before cryomilling (the lower pattern) and after cryomilling for different times. Figure 2(b) is for the (111) peak for powders cryomilled for $7 \mathrm{~h}$ demonstrating the broadening of the peak for which the small crystallite size is contributing. Figure 3 presents the effect of milling time on the crystallite size of the milled powders as calculated by the Scherrer formula discussed above. It is seen that after $7 \mathrm{~h}$ of cryomilling, the crystal szie is refined to around $23 \mathrm{~nm}$.

A TEM bright-field image of $\mathrm{Al}$ powder cryomilled for $7 \mathrm{~h}$, as presented in Figure 4(a), indicates nanosized grains $(<100 \mathrm{~nm})$. A histogram of the grain size distribution, based on the analysis of 300 grains, for this specimen is presented in Figure 4(b) which illustrates the frequency versus grain size range. The average grain size for TEM measurements is $19 \mathrm{~nm}$ with standard deviation of $6 \mathrm{~nm}$. This value is essentially similar to that based on XRD measurements.
After drying the powders, as explained previously, the particles were charged into a graphite die $10 \mathrm{~mm}$ in diameter between two fitting punches. The die was placed in a HFIHS press and pressed to $50 \mathrm{MPa}$. At that point heating was emenced with a specified heating rate. The pressure was maintained throughout the whole test via an LVDT. Figure 5 shows the effect of sintering temperature (350, 450, 500, and $550^{\circ} \mathrm{C}$ ) on the Vickers hardness in (a), percentage of full density in (b), and crystal size in (c) for a constant sintering time of 3 minutes and a heating rate of $800^{\circ} \mathrm{C} / \mathrm{min}$, for the powders cryomilled for 7 hours. It was seen that as the sintering temperature increased to $550^{\circ} \mathrm{C}$, the hardness, the density, and the crystal size increased but the maximum crystal size was still around $75 \mathrm{~nm}$ and this is mainly attributed to high heating rate applied. Figure 6 presents the effect of sintering time of 1, 2, and 3 minutes on the Vickers hardness in (a) and percentage of full density in (b) for a heating rate of $800^{\circ} \mathrm{C} / \mathrm{min}$, for the powders cryomilled for 7 hours. For the purpose of comparison, the hardness values of a bulk similar composition of aluminum alloy (commercial purity $1050 \mathrm{AA}$ ) in as-received rolled condition, annealed condition, and equal channel angular pressed to 8 passes via route $\mathrm{Bc}[16]$ are presented. It is obvious that with cryomilling and HFIHS the hardness achieved is comparable to the hardness achieved due to another severe plastic deformation technique that is classified as a top down approach namely, equal channel angular pressing (ECAP) that is quite a lengthy process. It is seen that with increasing sintering time, the hardness and density increase.

To achieve better densification, a lower heating rate of $400^{\circ} \mathrm{C} / \mathrm{min}$ is used. Figure 7 shows the effect of different sintering conditions of two temperatures of $500^{\circ} \mathrm{C}$ and $550^{\circ} \mathrm{C}$ with two sintering times of 1 and 3 minutes on the crystal size in (a), percentage of full density in (b), and hardness in (c). The heating rate used for all the sintering conditions displayed in Figure 7 is $400^{\circ} \mathrm{C} / \mathrm{min}$ and the powders are those milled for 7 hours. The crystal size ranged from $82 \mathrm{~nm}$ to $140 \mathrm{~nm}$ 


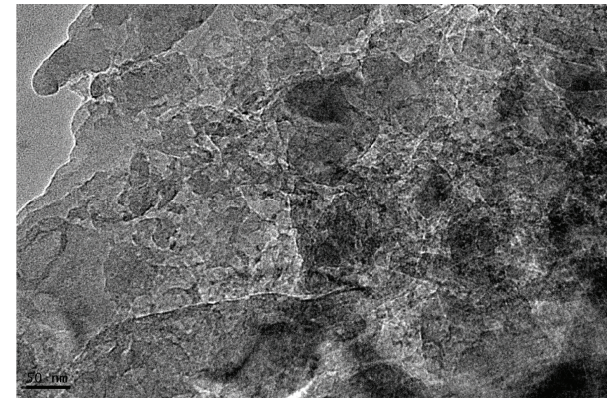

(a)

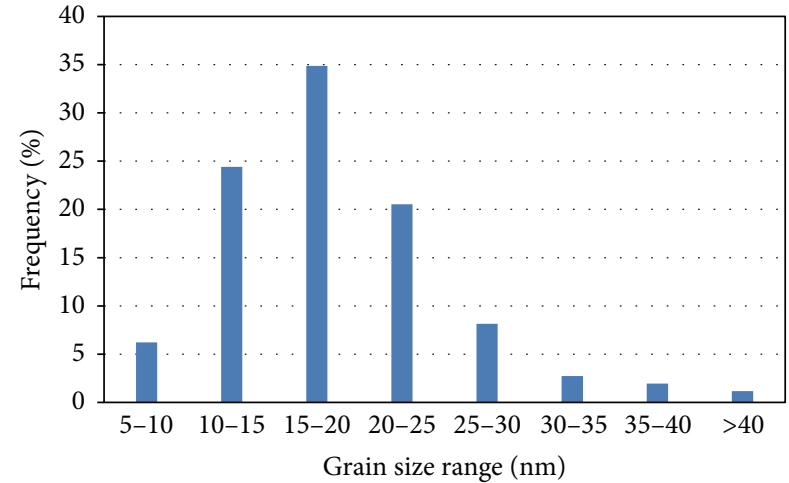

(b)

FIgURE 4: Cryomilled Al powder for 7 hrs: (a) TEM bright-field image and (b) grain size distributions for the TEM micrograph in (a).

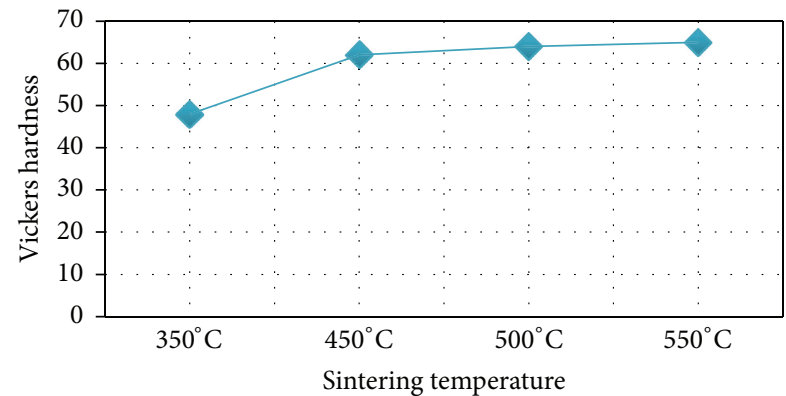

(a)

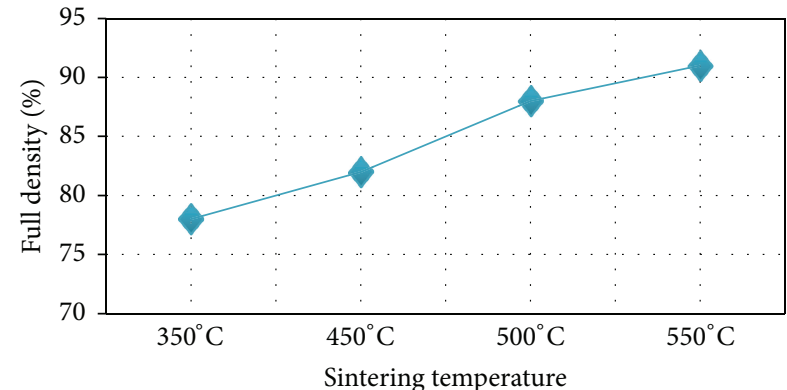

(b)

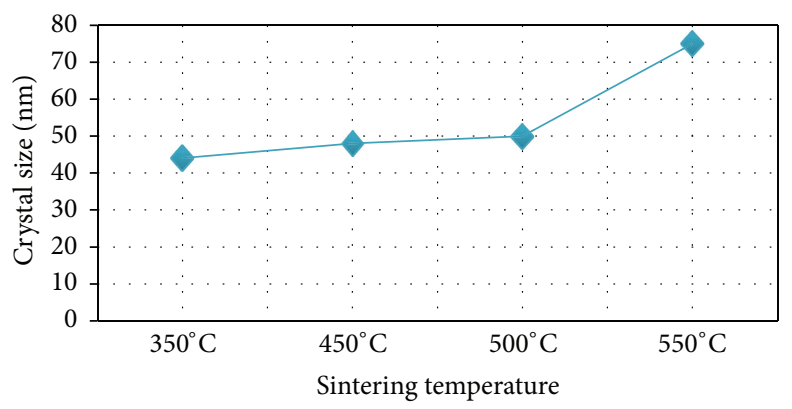

(c)

FIGURE 5: Effect of sintering temperature for the powders cryomilled for 7 hours for sintering of 3 minutes and high heating rate: (a) Vickers hardness, (b) percentage of full density, and (c) crystal size.

for the sinetring conditions of $500\left({ }^{\circ} \mathrm{C}\right) / 400\left({ }^{\circ} \mathrm{C} / \mathrm{min}\right) / 1$ ( $\mathrm{min})$ and $550\left({ }^{\circ} \mathrm{C}\right) / 400\left({ }^{\circ} \mathrm{C} / \mathrm{min}\right) / 3(\mathrm{~min})$, respectively. The percentage of full density ranged from $93 \%$ to $95 \%$ for the sinetring conditions of $500\left({ }^{\circ} \mathrm{C}\right) / 400\left({ }^{\circ} \mathrm{C} / \mathrm{min}\right) / 1(\mathrm{~min})$ and $550\left({ }^{\circ} \mathrm{C}\right) / 400\left({ }^{\circ} \mathrm{C} / \mathrm{min}\right) / 3(\mathrm{~min})$, respectively. The hardness ranged from 65 to $140 \mathrm{HV}$ for the sinetring conditions of $500\left({ }^{\circ} \mathrm{C}\right) / 400\left({ }^{\circ} \mathrm{C} / \mathrm{min}\right) / 1(\mathrm{~min})$ and $550\left({ }^{\circ} \mathrm{C}\right) / 400\left({ }^{\circ} \mathrm{C} / \mathrm{min}\right) / 3$ (min), respectively.

Figure 8 shows the effect of heating rate for the powders cryomilled for 7 hours on crystal size in (a) and densification in (b) for $500^{\circ} \mathrm{C}$ and two sintering times of 1 and 3 minutes. It is obvious that lowering the heating rate resulted in larger crystal size but better densification. For example, at the condition of $500^{\circ} \mathrm{C} / 400\left({ }^{\circ} \mathrm{C} / \mathrm{min}\right) / 3 \mathrm{~min}$, the density reaches $94 \%$ of theoretical density and the grain size is still below $100 \mathrm{~nm}$.
Figure 9 shows the secondary electron images for the fractured surfaces of samples consolidated at the same temeprature of $500^{\circ} \mathrm{C}$ and the same time of 3 minutes but different heating rates of $800^{\circ} \mathrm{C} / \mathrm{min}$ in (a) and $400^{\circ} \mathrm{C} / \mathrm{min}$ in (b). Figure 9 presents a sample from a thorough investigation of the effect of heating rate on the cavitations morphology which constituted another 15 similar images for each sample. It was concluded that with high heating rates the frequency of observing a void in the image was always higher with consistently relatively bigger voids in the high heating rate consolidated sample.

Figure 10(a) shows the effect of sintering temeprature for a constant sintering time of $3 \mathrm{~min}$ on the true stress-strain response obtained in simple compression of the consolidated samples. The trend is obvious that higher flow stress levels are 


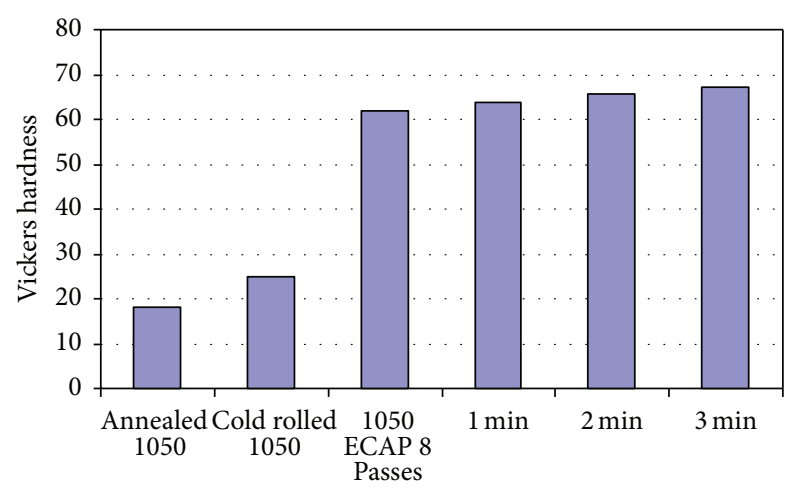

(a)

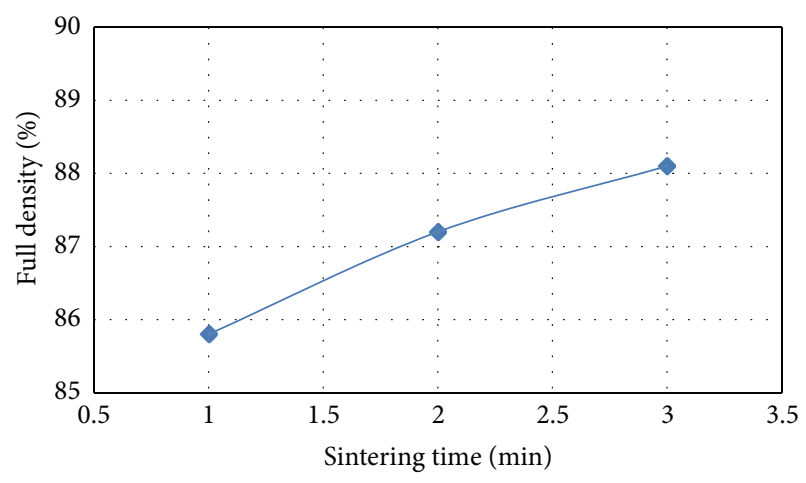

(b)

FIGURE 6: Effect of sintering time on Vickers hardness in (a) as compared to differently processed $1050 \mathrm{Al}$ and percentage of full density in (b) for the powders cryomilled for 7 hours at a sintering temperature of $500^{\circ} \mathrm{C}$.

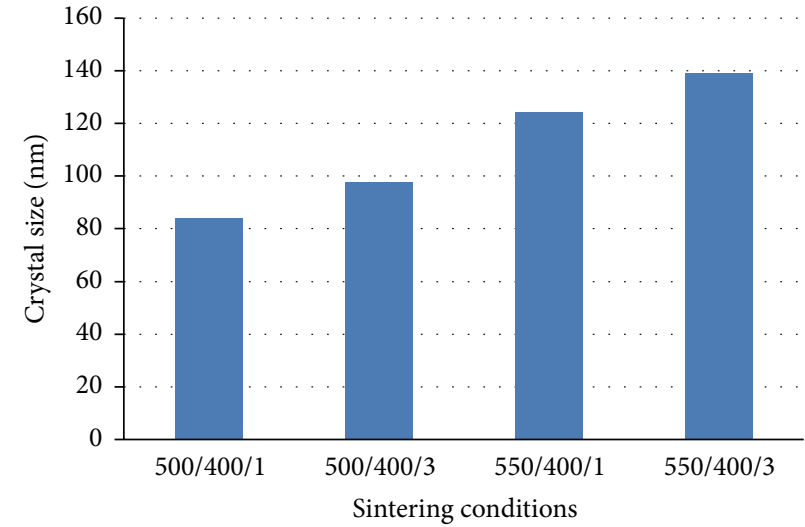

(a)

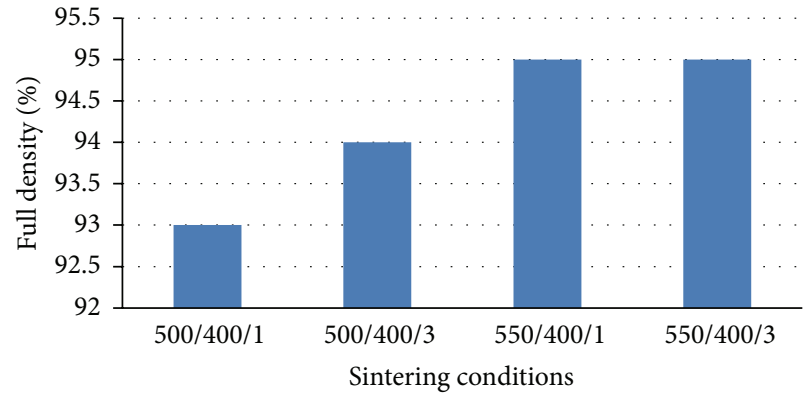

(b)

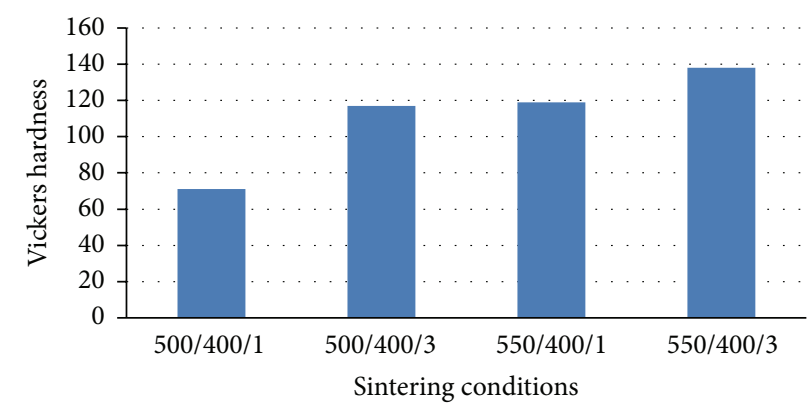

(c)

Figure 7: Effect of different sintering conditions (sintering temp. $\left({ }^{\circ} \mathrm{C}\right) /$ heating rate $\left({ }^{\circ} \mathrm{C} / \mathrm{min}\right) /$ sintering time $($ minutes $)$ ) on crystal size in $(\mathrm{a})$ percentage of full density in (b) and Vickers hardness in (c) for the powders cryomilled for 7 hours.

exhibited for the higher sinetring temeprature. Figure 10(b) shows the effect of sintering time for a constant sintering temeprature of $500^{\circ} \mathrm{C}$. The highest flow stress was for the highest sinetring time of 3 minutes. The heating rate used for these consolidated samples was $800^{\circ} \mathrm{C} / \mathrm{min}$. The previous two findings were mainly attributed to the higher densification levels exhibited for the higher sintering temeprature and the higher sintering time. Figure 11 shows the true stress strain response in simple compression of a consolidated sample after sintering at temperature of $500^{\circ} \mathrm{C}$ for 3 minutes at a high heating rate of $800^{\circ} \mathrm{C} / \mathrm{min}$ (crystallite size is $50 \mathrm{~nm}$ ). The true stress strain responses of a consolidated sample of the as-received powders under the same sintering conditions and ECAP processed $\mathrm{Al}$ to 8 passes are also shown in the figure [16]. The superior strength levels for the consolidated cryomilled powder are obvious (the yield strength of $270 \mathrm{MPa}$ is almost as twice as that of ECAPed specimen, $130 \mathrm{MPa}$, and more than five times the yield strength of the as-received consolidated powders, $48 \mathrm{MPa}$ ). The compression test of the consolidated sample was interrupted with the first visual sign 


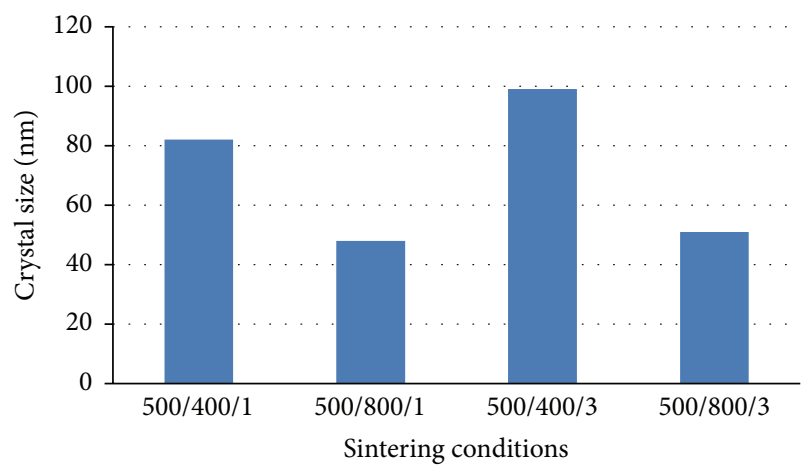

(a)

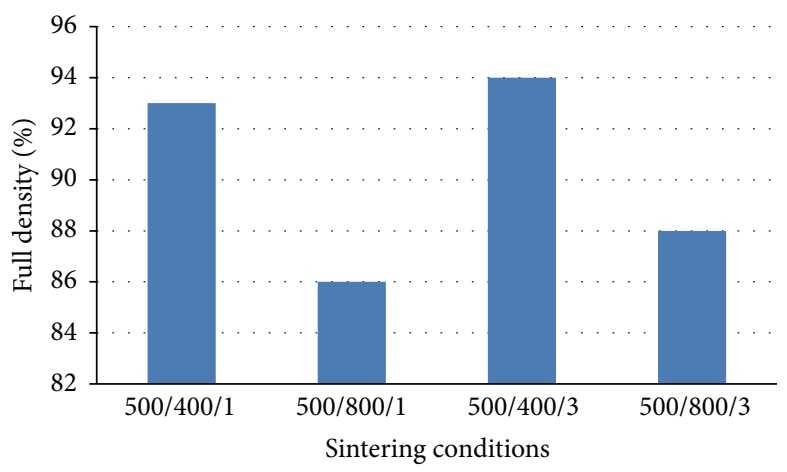

(b)

FIGURE 8: Effect of heating rate on crystal size in (a) and percentage of full density in (b) for the sintering temperature of $500^{\circ} \mathrm{C}$ and for two sintering times of 1 and 3 minutes.

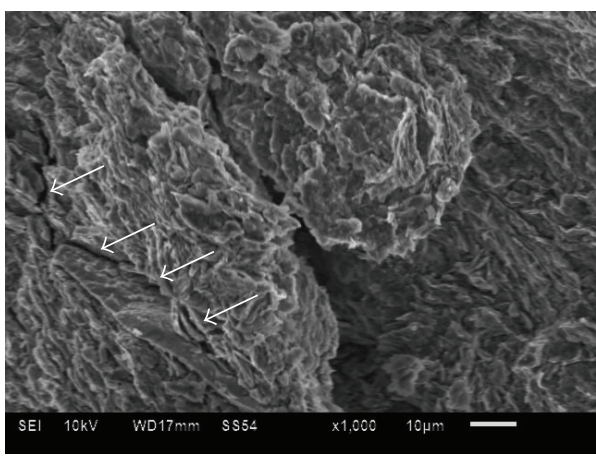

(a)

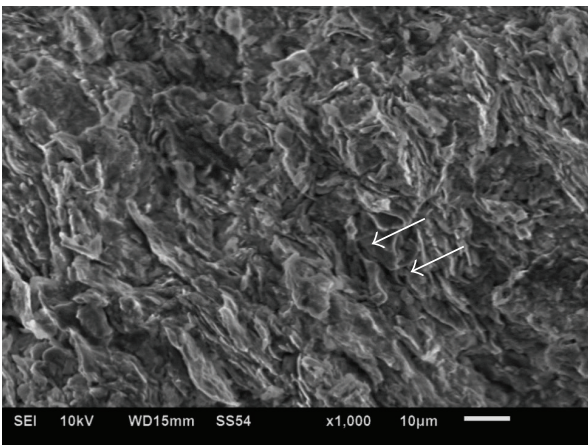

(b)

FIGURE 9: Secondary electron image of the fractured surface for samples consolidated at $800^{\circ} \mathrm{C} / \mathrm{min} / 500^{\circ} \mathrm{C} / 3 \mathrm{~min}$ in (a) and at $400^{\circ} \mathrm{C} / 500^{\circ} \mathrm{C} / 3 \mathrm{~min}$ in (b).

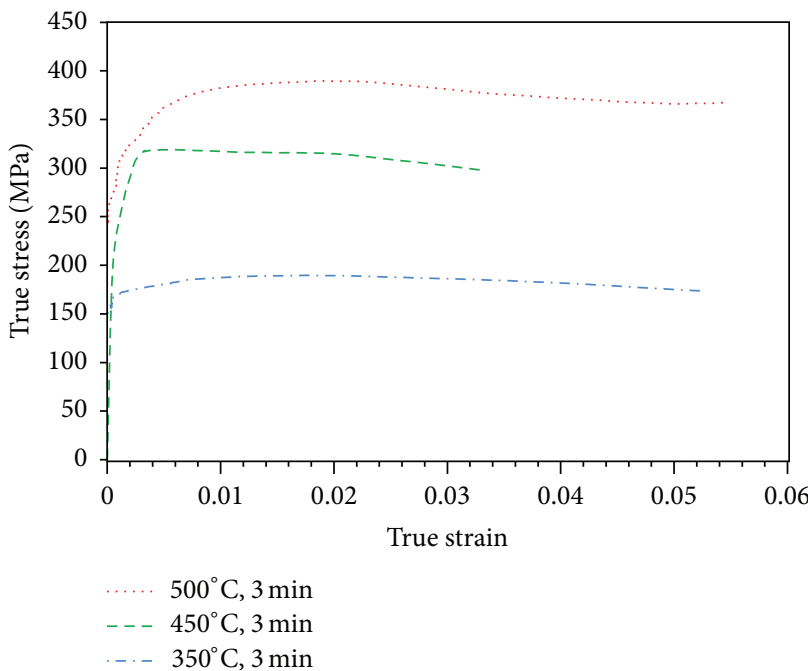

(a)

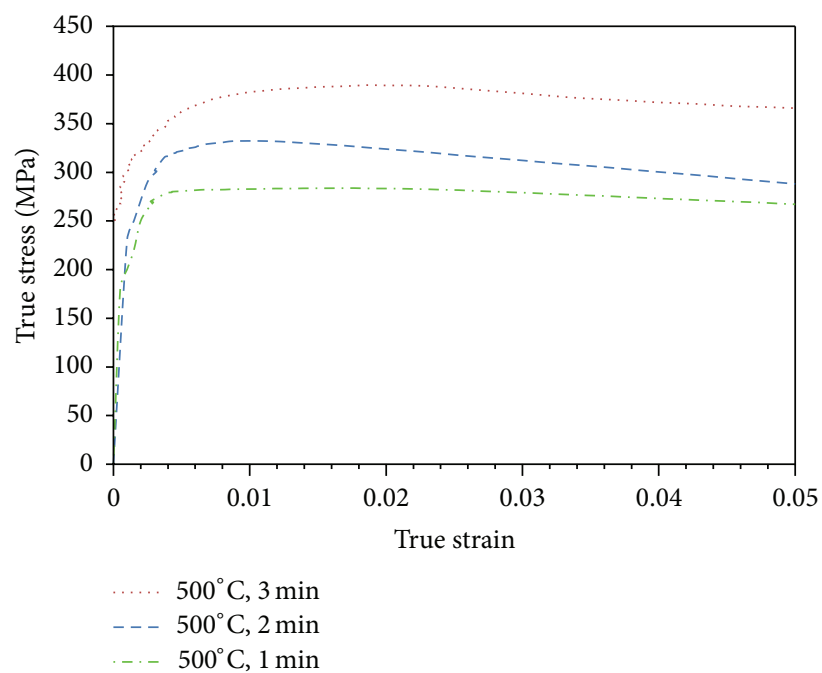

(b)

FIGURE 10: True stress strain response in simple compression of consolidated samples at different sintering temperatures for a constant sintering time of 3 minutes in (a) and for different sintering times for a constant sintering temperature of $500^{\circ} \mathrm{C}$. The heating rate used was $800^{\circ} \mathrm{C} / \mathrm{min}$. 


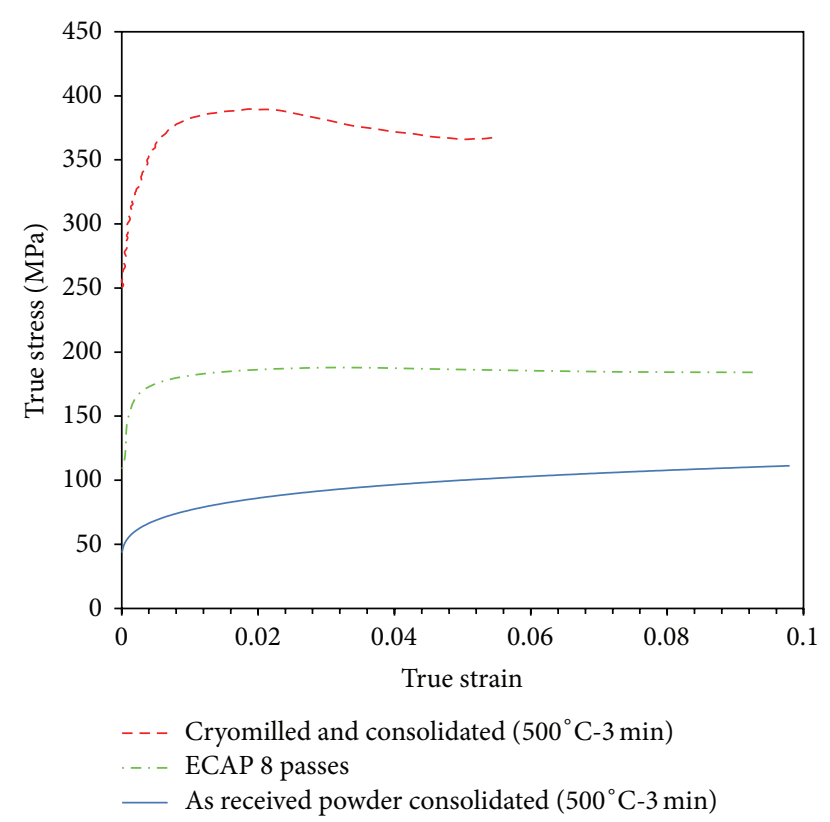

FIgURE 11: True stress strain response in simple compression for consolidated samples from the $7 \mathrm{hrs}$ cryomilled powders. The heating rate used for this sample was $800^{\circ} \mathrm{C} / \mathrm{min}$. Also shown in the figure are the true stress strain responses for as-received powder consolidated at $500^{\circ} \mathrm{C}$ for $3 \mathrm{~min}$., and an ECAPed specimen [16].

of failure of the sample. However, it can be seen in Figure 11 that the consolidated sample is capable of strain hardening up to an ultimate strength of $390 \mathrm{MPa}$. On the other hand, ECAPed specimen just showed strain hardening over a very short amount of strain to a constant ultimate strength of $180 \mathrm{MPa}$.

Han et al. [5] studied the deformation of cryomilled Al 7.5\% Mg consolidated via hot isostatic pressing and conventional $5083 \mathrm{Al}$ alloys subjected to identical heat treatments. The grain size of $5083 \mathrm{Al}$ was measured to be $5 \mu \mathrm{m}$, and that for the cryomilled alloy was approximately $300 \mathrm{~nm}$. As reported, the strength of the cryomilled alloy is much higher than that of the 5083 alloy, by approximately a factor of 4 . The ductility of the cryomilled alloy as well as the strain hardening rate is reduced. They attributed the high strength to grain size effect, solid solution strengthening, dislocation strengthening, and the presence of nanoscale oxides or nitrides or carbides dispersoids.

The study of thermal stability of nanocrystalline materials has been recently reviewed by Koch [17]. Such study is important for both technological and scientific reasons. From a technological point of view, the thermal stability is important for consolidation of nanocrystalline particulates without coarsening the microstructure. The synthesis of nanocrystalline materials via milling processes results in particulate products which must be consolidated into bulk form. Since most consolidation processes involve both heat and pressure, the temperature stability of the nanoscale microstructure is always at danger. The optimum goal of particulate consolidation is to attain essentially $100 \%$ theoretical density and good particulate bonding while preventing or minimizing grain growth of the nanocrystalline grains. Understanding the scientific nature of stability, grain growth of nanocrystalline microstructures is a criterion for allowing strategies for minimizing grain growth to be developed. Attempt was made to study the thermal stability of loose cryomilled Al powder with crystallite size of $26 \mathrm{~nm}$ using the modified classical kinetic grain growth theory to include pinning forces that exert drag on grain boundary migration [18]. The thermal stability in a broader sense involves not only the stability of the grain structure, that is, the microstructure, but also the stability of the structure of the grain boundaries in nanocrystalline materials.

Grain growth in nanocrystalline materials has been reviewed by Suryanarayana [19]. In spite of the high driving force for grain growth and the observation of grain growth, at least abnormal grain growth, even at very low homologous temperatures, significant stabilization of nanocrystalline grain structures has been observed in many materials. The one common feature of such materials is that they are multicomponent, that is, either alloys or contain impurities. There are two basic approaches in which grain growth can be reduced. The first is the kinetic one in which the grain boundaries are pinned in various ways to decrease grain boundary (GB) mobility while the second is the thermodynamic one in which the driving force for grain growth is lowered by reducing the GB energy. In the kinetic approach the GB mobility is reduced by various possible mechanisms [20-24]. The kinetic approach, assumes that the GB energy is constant, as usually considered in highly pure and coarsegrained polycrystalline materials [25]. Strictly speaking, GB energy cannot be considered as constant covering the grain growth of nanosized alloy with a large volume fraction of interfacial boundaries. On the other hand, the thermodynamic approach considers the reduction of the GB energy as a result of solute segregation. Since the driving force for grain growth is directly proportional to the GB energy, reducing the GB energy should minimize grain growth. Addition of solute atoms that segregate to the grain boundaries will affect the GB energy. Based on this concept models have been set by Weissmüller [26, 27], Kirchheim [28], and Liu and Kirchheim [29]. The grain size at the metastable thermodynamic equilibrium was found in their analysis to be determined by the GB energy, the enthalpy change of grain boundary segregation, and the solute excess of an equivalent GB monolayer at saturation. The thermal stability of grain boundaries in nanocrystalline materials is influenced greatly by the inherent nonequilibrium characteristics of these boundaries, and therefore the grain growth should be a kinetics process controlled by a thermodynamic effect [30, 31]. The GB energy is reduced with grain growth and as solute segregation is strengthened upon grain growth, GB energy decreases and thus inhibits grain growth rate. Segregation of solute and/or impurity atoms to the grain boundaries appears to be an effective method for stabilization of nanocrystalline grain size.

Figures 12(a)-12(b) show the relation between the crystallite size, $d$ in $\mathrm{nm}$, and the sintering temperature for cryomilled loose powder of $\mathrm{Al}$ [18] and consolidated powder at the present investigation. The loose powder was heated 


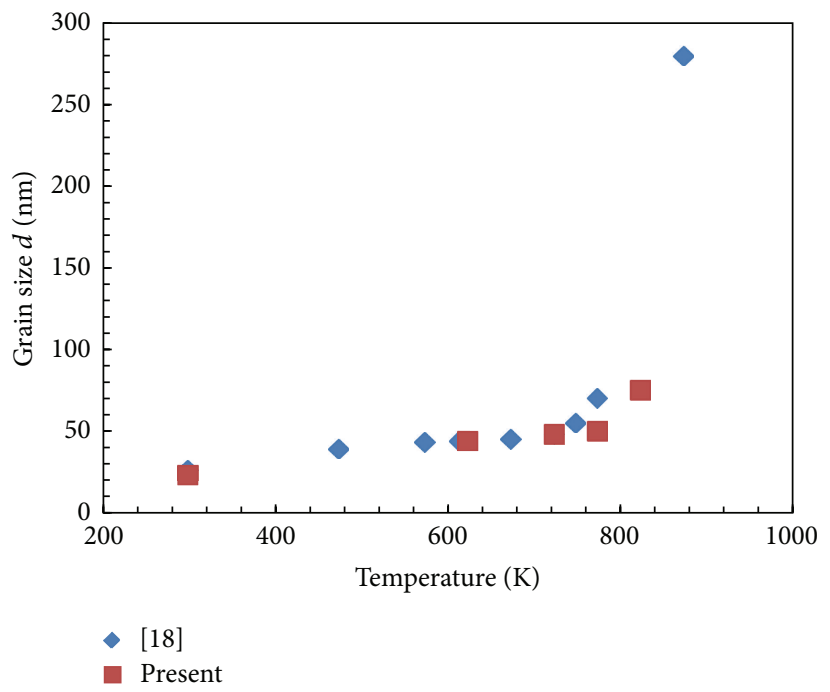

(a)

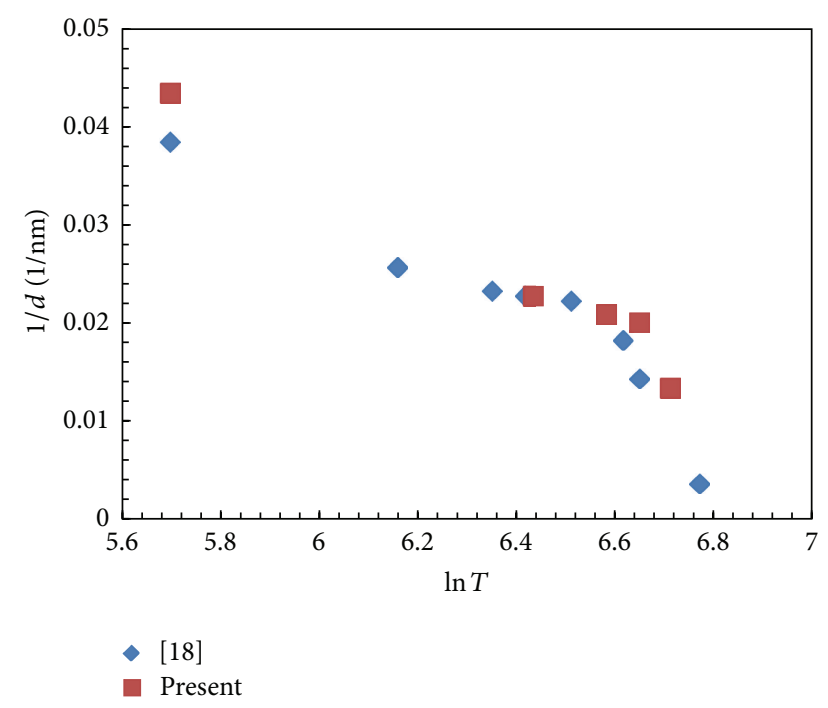

(b)

Figure 12: (a) Correlation between the grain size, $\mathrm{d}(\mathrm{nm})$ and Temperature $(\mathrm{K})$ and (b) relation between $1 / d$ and $\ln T$.

isothermally for $5 \mathrm{~min}$ at the required temperature, while the present powder was consolidated into bulk samples under vacuum using HFIHS process at pressure of $50 \mathrm{MPa}$. The starting powders have similar crystallite size of $26 \mathrm{~nm}$ [18] and $23 \mathrm{~nm}$, respectively. Figure 12(b) suggests the presence of two regions of linear dependence between $(1 / d)$ and $\ln T$, giving support to the prediction of the kinetic models of grain growth as controlled by thermodynamic process [28-31].

The result for the nano-grain size obtained in the present $\mathrm{Al}$ alloy is in agreement with the compiled data for cryomilling and the prediction of a dislocation model for minimum grain size obtainable via this severe deformation process [32]. Very recently, it was demonstrated that bulk nc-Al samples whose grain sizes are less than $100 \mathrm{~nm}$ can be produced by consolidating cryomilled Al powders containing diamantane [24], whose size is in the range of $2-5 \mathrm{~nm}$, via hot isostatic pressing (HIP) followed by trap extrusion (high strain extrusion) at room temperature,; and that the average grain size for cryomilled bulk nc-Al containing diamantane was consistently about one half $(69 \mathrm{~nm})$ of that for the powders that do not contain diamantane at the same temperature $(150 \mathrm{~nm})$ [33].

\section{Conclusions}

(1) Commercially pure aluminum powder was cryomilled for 7 hours to produce nanostructured powder with an average grain (crystallite) size of $23 \mathrm{~nm}$.

(2) The consolidated powders using HFIHS at pressure of $50 \mathrm{MPa}$ resulted in compact solids with density of $\sim 95 \%$ of theoretical density of $\mathrm{Al}$ with grain size $<100 \mathrm{~nm}$.

(3) The heating rate used in HFIHS has a great effect on the final compact properties including grain size, density, and mechanical properties.
(4) The compact solid showed superior strength as compared to another severely plastic deformation process (ECAP).

(5) Controlling the sintering parameters in HFIHS can give solid compact with nanoscale grain size with superior mechanical properties.

(6) The thermal stability of nanostructured powders is in harmony with the kinetics models based on the thermodynamic effects.

\section{Acknowledgments}

The authors would like to acknowledge the support provided by the National Plan for Science and Technology (NPST), King Saud University, Saudi Arabia, under Project no. 08-ADV349-02. The useful discussion with Professor F. A. Mohamed, Department of Chemical Engineering and Materials Science, University of California, Irvin, CA, USA, is gratefully acknowledged.

\section{References}

[1] M. N. Rittner and T. Abraham, "Nanostructured materials: an overview and commercial analysis," JOM, vol. 50, no. 1, pp. 3637, 1998.

[2] H. G. Salem, S. El-Eskandarany, A. Kandil, and H. Abdul Fattah, "Bulk behavior of ball milled AA2124 nanostructured powders reinforced with TiC," Journal of Nanomaterials, vol. 2009, Article ID 479185, 12 pages, 2009.

[3] V. L. Tellkamp, A. Melmed, and E. J. Lavernia, "Mechanical behavior and microstructure of a thermally stable bulk nanostructured Al alloy," Metallurgical and Materials Transactions A, vol. 32, no. 9, pp. 2335-2343, 2001.

[4] J. Lee, F. Zhou, K. H. Chung, N. J. Kim, and E. J. Lavernia, "Grain growth of nanocrystalline Ni powders prepared by cryomilling," 
Metallurgical and Materials Transactions A, vol. 32, no. 12, pp. 3109-3115, 2001.

[5] B. Q. Han, D. Matejczyk, F. Zhou et al., "Communications: mechanical behavior of a cryomilled nanostructured Al-7.5 pct Mg alloy," Metallurgical and Materials Transactions A, vol. 35, no. 3, pp. 947-949, 2004.

[6] Y. Xun, E. J. Lavernia, and F. A. Mohamed, "Synthesis of nanocrystalline Zn-22 pct Al using cryomilling," Metallurgical and Materials Transactions A, vol. 35, no. 2, pp. 573-581, 2004.

[7] M. Zawarh and L. Shaw, "Microstructure and hardness of nanostructured Al-Fe-Cr-Ti alloysthrough mechanical alloying," Materials Science and Engineering A, vol. 355, pp. 37-49, 2003.

[8] B. Q. Han, Z. Lee, S. R. Nutt, E. J. Lavernia, and F. A. Mohamed, "Mechanical properties of an ultrafine-grained Al-7.5 Pct Mg alloy," Metallurgical and Materials Transactions A, vol. 34, no. 3, pp. 603-613, 2003.

[9] J. He, K. H. Chung, X. Liao, Y. T. Zhu, and E. J. Lavernia, "Mechanical milling-induced deformation twinning in Fcc materials with high stacking fault energy," Metallurgical and Materials Transactions A, vol. 34, no. 3, pp. 707-712, 2003.

[10] G. T. Gray III, "Deformation twinning in Al-4.8 wt\% Mg," Acta Metallurgica, vol. 36, no. 7, pp. 1745-1754, 1988.

[11] H. Huang, J. Ding, and P. G. McCormick, "Micro structural evolution of 304 stainless steel during mechanical milling," Materials Science and Engineering A, vol. 216, no. 1-2, pp. 178184, 1996.

[12] H. P. Klug and L. E. Alexander, X-Ray Diffraction Procedures for Polycrystalline and Amorphous Materials, John Wiley \& Sons, New York, NY, USA, 2nd edition, 1974.

[13] Z. Zhang, F. Zhou, and E. J. Lavernia, "On the analysis of grain size in bulk nanocrystalline materials via x-ray diffraction," Metallurgical and Materials Transactions A, vol. 34, no. 6, pp. 1349-1355, 2003.

[14] F. Zhou, D. Witkin, S. R. Nutt, and E. J. Lavernia, "Formation of nanostructure in $\mathrm{Al}$ produced by a low-energy ball milling at cryogenic temperature," Materials Science and Engineering A, vol. 375-377, no. 1-2, pp. 917-921, 2004.

[15] K. A. Khalil and A. A. Almajid, "Effect of high-frequency induction heat sintering conditions on the microstructure and mechanical properties of nanostructured magnesium/hydroxyapatite nanocomposites," Materials and Design, vol. 36, pp. 58-68, 2012.

[16] E. A. El-Danaf, M. S. Soliman, A. A. Almajid, and M. M. ElRayes, "Enhancement of mechanical properties and grain size refinement of commercial purity aluminum 1050 processed by ECAP," Materials Science and Engineering A, vol. 458, no. 1-2, pp. 226-234, 2007.

[17] C. C. Koch, "Structural nanocrystalline materials: an overview," Journal of Materials Science, vol. 42, no. 5, pp. 1403-1414, 2007.

[18] F. Zhou, J. Lee, S. Dallek, and E. J. Lavernia, "High grain size stability of nanocrystalline Al prepared by mechanical attrition," Journal of Materials Research, vol. 16, no. 12, pp. 3451-3458, 2001.

[19] C. Suryanarayana, "Nanocrystalline materials," International Materials Reviews, vol. 40, no. 2, pp. 41-64, 1995.

[20] H. J. Höfler and R. S. Averback, "Grain growth in nanocrystalline $\mathrm{TiO}_{2}$ and its relation to vickers hardness and fracture toughness," Scripta Metallurgica et Materiala, vol. 24, no. 12, pp. 2401-2406, 1990.

[21] K. Boylan, D. Ostrander, U. Erb, G. Palumbo, and K. T. Aust, "An in-situ tem study of the thermal stability of nanocrystalline NiP," Scripta Metallurgica et Materiala, vol. 25, no. 12, pp. 27112716, 1991.
[22] A. Michels, C. E. Krill, H. Ehrhardt, R. Birringer, and D. T. Wu, "Modelling the influence of grain-size-dependent solute drag on the kinetics of grain growth in nanocrystalline materials," Acta Materialia, vol. 47, no. 7, pp. 2143-2152, 1999.

[23] Z. Q. Gao and B. Fultz, "Inter-dependence of grain growth, Nb segregation, and chemical ordering in FeSiNb nanocrystals," Nanostructured Materials, vol. 4, no. 8, pp. 939-947, 1994.

[24] K. Maung, R. K. Mishra, I. Roy, L.-C. Lai, F. A. Mohamed, and J. C. Earthman, "Thermal stability of cryomilled nanocrystalline aluminum containing diamantane nanoparticles," Journal of Materials Science, vol. 46, no. 21, pp. 6932-6940, 2011.

[25] J. E. Burke and D. Turnbull, "Recrystallization and grain growth," Progress in Metal Physics, vol. 3, pp. 220-292, 1952.

[26] J. Weissmüller, "Alloy effects in nanostructures," Nanostructured Materials, vol. 3, no. 1-6, pp. 261-272, 1993.

[27] J. Weissmuller, "Alloy thermodynamics in nanocrystals," Journal of Materials Research, vol. 9, pp. 4-7, 1994.

[28] R. Kirchheim, "Grain coarsening inhibited by solute segregation," Acta Materialia, vol. 50, no. 2, pp. 413-419, 2002.

[29] F. Liu and R. Kirchheim, "Grain boundary saturation and grain growth," Scripta Materialia, vol. 51, no. 6, pp. 521-525, 2004.

[30] X. Song, J. Zhang, L. Li, K. Yang, and G. Liu, "Correlation of thermodynamics and grain growth kinetics in nanocrystalline metals," Acta Materialia, vol. 54, no. 20, pp. 5541-5550, 2006.

[31] Z. Chen, F. Liu, W. Yang, H. Wang, G. Yang, and Y. Zhou, "Influence of grain boundary energy on the grain size evolution in nanocrystalline materials," Journal of Alloys and Compounds, vol. 475, no. 1-2, pp. 893-897, 2009.

[32] F. A. Mohamed, "A dislocation model for the minimum grain size obtainable by milling," Acta Materialia, vol. 51, no. 14, pp. 4107-4119, 2003.

[33] K. Maung, J. C. Earthman, and F. A. Mohamed, "Inverse HallPetch behavior in diamantane stabilized bulk nanocrystalline aluminum," Acta Materialia, vol. 60, pp. 5850-5857, 2012. 

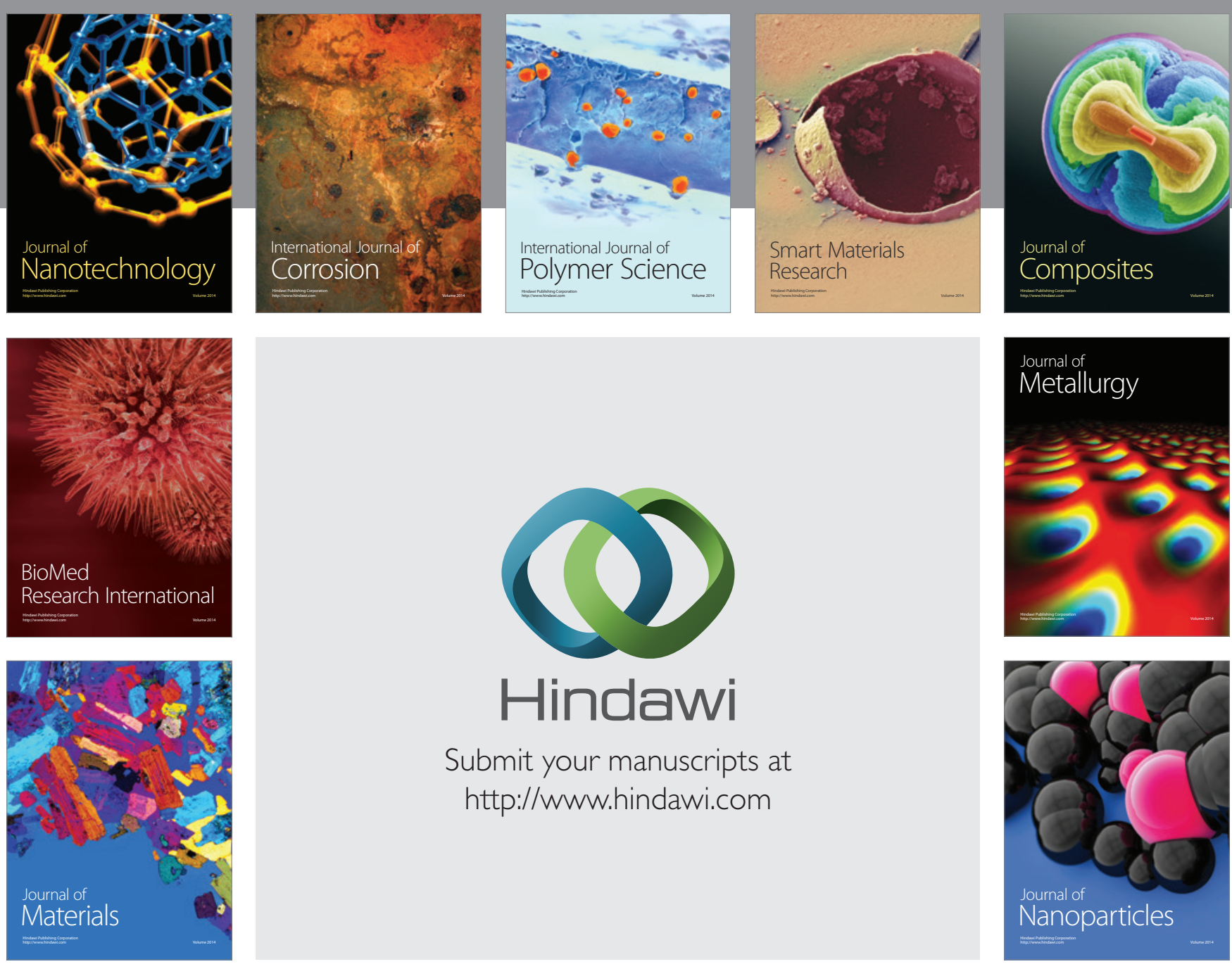

Submit your manuscripts at http://www.hindawi.com
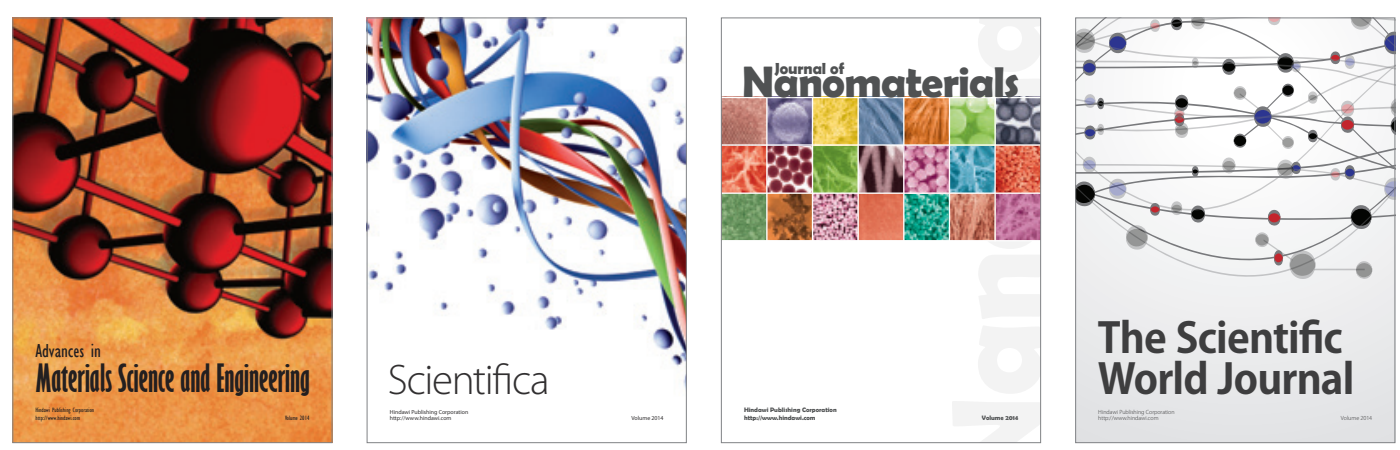

\section{The Scientific World Journal}
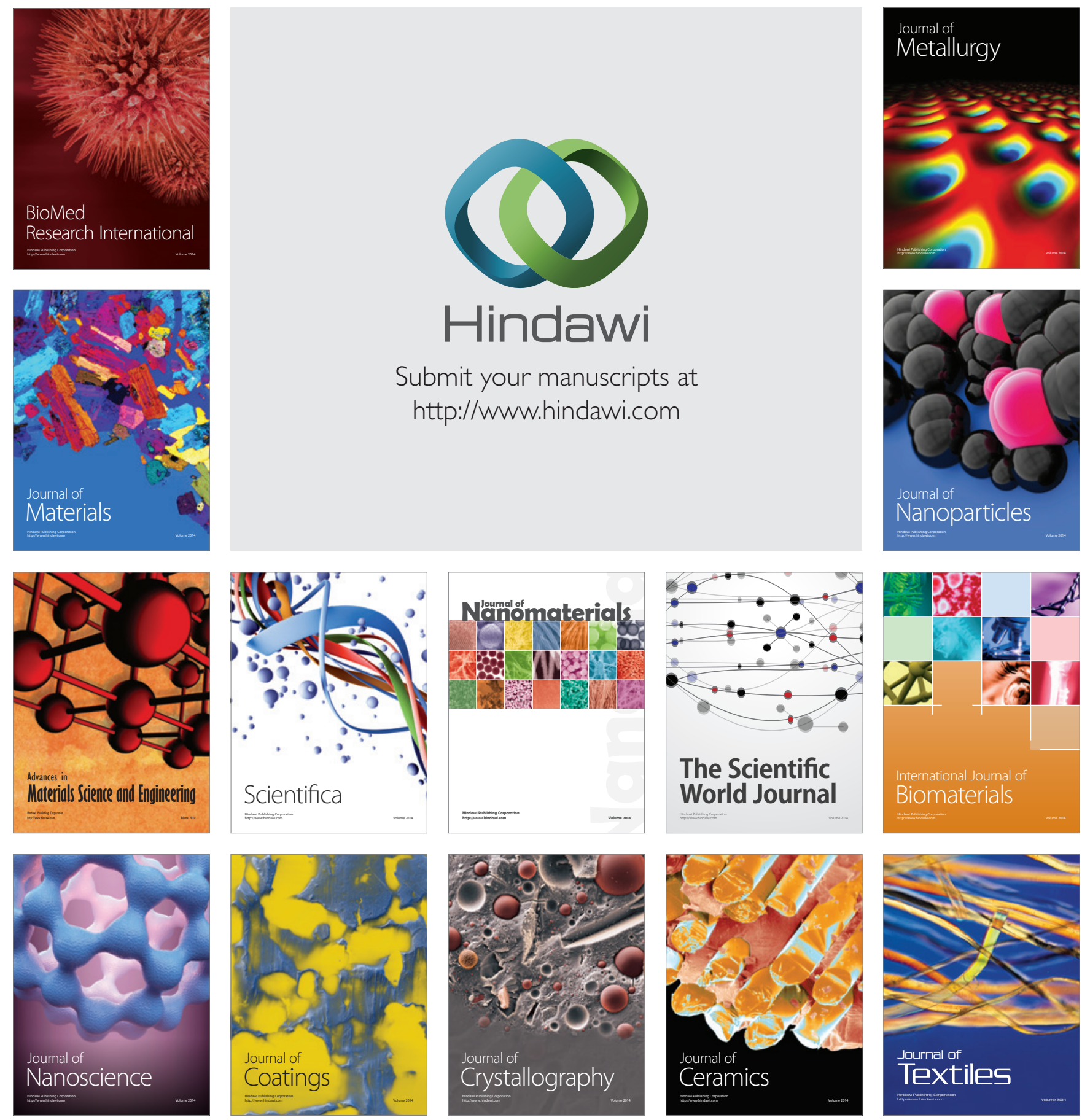